\title{
The effect of educational methods on creativity of pre-school children: A case study
}

\author{
Maryam Bagherpour $^{a^{*}}$ and Babak Shamshiri ${ }^{\mathrm{b}}$
}

${ }^{a}$ Msc. Graduate in Curriculum Planning, Iran

${ }^{b}$ College of Educations and Psychology, Shiraz University, Iran

CHRON I C LE A B S T RACT

\begin{tabular}{l}
\hline Article history: \\
Received: January 11,2018 \\
Received in revised format: \\
March 3, 2018 \\
Accepted: May 10, 2018 \\
Available online: \\
May 14, 2018 \\
\hline Keywords: \\
Language learning \\
Creativity \\
Ban Ben Bon \\
Effectiveness \\
Statistical test
\end{tabular}

\begin{abstract}
The aim of this study was to analyze the effectiveness of the educational method so-called "Ban Ben Bon" on language learning and creativity of pre-school children. The study was a semi-experimental one and its statistical population included 198 children studying in the preschools of Shiraz, Iran. The sample group consisted of 30 preschool children which were selected randomly. The research tool included Torrance test of creative thinking and function test including 11 questions for measuring the reading skill in preschool children. There were five preschools in Golestan town and six children were selected randomly from each five preschools. The children were asked to answer the questions of the function test, and the educating method of Ban Ben Bon was used for educating them. The results show that the educating method of Ban Ben Bon had significant effect on language learning and reading but it had insignificant effect on the creativity of preschool children. Based on statistical analysis and hypothesis testing, it was found that among four elements of creativity, including flexibility, innovation, expansion and fluidity, the method just had a significant effect on innovation.
\end{abstract}

\section{Introduction}

No one can deny the importance of training and educating the preschool children. Training and educating are considered as the most important factors in the general growth of children especially in the elementary school. The first six years of a child's life is of great importance because the growth of a child is much faster in this stage than other stages. Training and educating in the preschool course provide the children with the opportunity to face with experiments, objects and various locations, and learn and experience. Teachers' creativity is another important factors, which help growth of preschool children. Kemple and Nissenberg (2000) assessed how creativity of teachers affects students' creativity development based on study conducted on more than 90 preschool and elementary school teachers. Preschool courses provide many opportunities for the children to meet adults, other groups and peers and make an interactive and significant relationship with them. Craft $(2001,2003)$ examined cultural, environmental and ethical limitations on creativity and argued that the creativity is value and culture specific. In another related work, Chae (2003) examined a creativity test on 1366 Korean preschool children and proposed the following

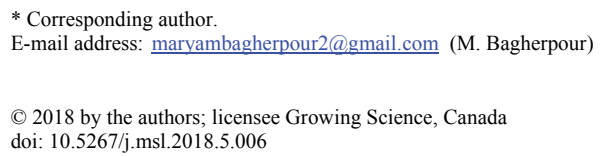


steps for improvement of creativity in children: "test translation, test implementation, scoring, selection and training of test agents and graders, norm construction, and score interpretation".

Also, Plowman and Stephen (2005) studied a development of an information technology strategy for preschool children. They examined their proposed approach using collection of evidences and through conducting interviews with at least two practitioners in the field. McPake et al. (2013) explored different approaches in developing of communication by domestic digital technologies ranging from computers and mobile phones to MP3 players and technological games. They concluded that digital technologies have some effects on doing creative tasks. Although the relationship between creativity and organization has been studied in the literature (Ahmadi \& Emamipour, 2013), however, our focus in this paper is to analyze the effect of educational methods on creativity in children.

In Iran, an educating game entitled "the Ban Ben Bon" is used which has three educating packages. The Ban Ben Bon is an educating and purposeful entertaining game which is designed and developed by a company in Iran to improve the reading skill of children. This game makes use of a novel style of educating and is played with some cards. On each card, a word is written on the lower part, and its image is shown on the upper part of the card. When the card is shown to a child, he/she tries to make a relationship between the word and the image in his/her brain. Then some other cards are shown to the child in which the word is written but there is no image. Then the child should find the image related to that word. This game can be played in the opposite way as well. In other words, the teacher can show an image to the child and then ask him/her to find its word on the cards. In fact, the aim of designing Ban Ben Bon game is to educate reading skills. As a matter of fact, Lavrentev (2014) discussed how joint activity between teacher and children might affect thinking approach and creativity of children.

In this study, all the elements of creativity were paid attention. The aim of this study is to investigate the role of Ban Ben Bon on creativity, language learning and reading skill in the preschool children. Moreover, two educating methods including the traditional and modern method were compared to find out which method is more effective in improving the reading skill in preschool children.

\section{Statement of the Problem}

Considering the importance of reading skill in preschool children, many efforts have been made in this regard to help children read the books and texts depending on their ages. For many years, experienced teachers were interested in teaching reading to the preschool students but they were not successful in this field. The language learning books published by the best and most reputable Iranian publications include some pictures and images which teach just the first and the last letters of the words, so that the child can just diagnose that two words such as Apple and Apricot both start with a letter, A, but the child cannot read the whole word.

When children learn to read books and various texts, they can add to their knowledge and learn and use more words. Moreover, they can nourish their creativity through reading imaginative stories, and then in the next steps they can make the end of the story as they wish and nourish their creativity in this way. Therefore, the educating game of Ban Ben Bon can be used to teach the reading skill to preschool children. In this game, first different cards are shown to the children in which the image is on the upper part and the related word is on the lower part. In the next stage, some other cards are shown to children in which the word is shown in the lower part but there is no image on the upper part. The related image is shown on the back of the card. Afterwards, the word is shown to children and then the back of the card is shown in which the image can be found. Teachers can play this game in the opposite direction. In other words, first the image is shown to children and then the back of the card in which the word is written is shown to them. In the next stage, the image is shown to the child and then the child is asked to find the word related to. We can also show the word and then ask the child to find the related image. Using this 
method, the child relates the whole word to its image. This is a modern educating method. In the traditional educating methods, the images are shown to the child and then the child is asked to find the first and the last letters of its written word.

The issues related to language learning, reading and creativity are very important but unfortunately very few studies have been conducted on this field. In Iran, this issue has not been studied in a comprehensive and focused way. Considering the importance of this issue, the present study aims at studying the effect of the educating method of Ban Ben Bon on creativity and language learning of preschool children.

This study tries to answer the following questions:

How does the educating method of Ban Ben Bon affect the reading skills of children? To what extent do the children can read the texts related to their age after they are educated by Ban Ben Bon?

Can children read the whole words in newspaper and journals after being trained by Ban Ben Bon?

Does Ban Ben Bon have any relationship with the creativity of children?

It is not clear to what extend Ban Ben Bon is effective in the skills of preschool children and the present study tries to find the answer of this question.

\section{The Importance and aim of the study}

\subsection{Importance of the research topic}

If children learn to read they can understand their world in an easier and better way and they can have a more broad views to the world. This extensive understanding can have a positive role in all aspects of the child's life. The studies conducted on preschool children show that children who learn reading and language at preschool have better progress in their lessons compared with children who do not learn the mentioned skills at preschool.

Creativity plays a significant role in life of children. A creative child can see things that a non-creative child cannot. Since the traditional method of training was found to be ineffective in teaching reading skills to children, this study investigates the effect of a novel educating method in reading skill and creativity of children.

\subsection{Aim of the Study and assumptions used}

The aim of this study is to investigate the effect of the educating method of Ban Ben Bon on language learning and creativity of preschool children in Golestan town, Shiraz, Iran.

\section{Assumptions used}

- The educating method of Ban Ben Bon has a significant effect on the creativity of male and female preschool children;

- The educating method of Ban Ben Bon has a significant effect on language learning in male and female preschool children;

- The educating method of Ban Ben Bon has a significant effect on innovation of male and female preschool children;

- The educating method of Ban Ben Bon has a significant effect on flexibility of male and female preschool children;

- The educating method of Ban Ben Bon has a significant effect on fluidity of male and female preschool children; 
- The educating method of Ban Ben Bon has a significant effect on extension extent of male and female preschool children.

\section{Statistical analysis}

This study is a semi-experimental one. The research design includes a pretest and a posttest with experiment and control groups. The experiment group is presented with educating method of Ban Ben Bon which is a novel educating method, and the control group is presented with the traditional method of educating (a language learning book).

\subsection{Statistical Population}

The statistical population of this study includes all the preschool children who were 6 years old and supposed to go to the first grade of elementary school in the following year. They lived in Golestan Town, Shiraz, Iran. The statistical population includes 198 preschool children (103 females and 95 males).

\section{Table 1}

The Frequency of Samples

\begin{tabular}{lll}
\hline Sex & Frequency & Percentage \\
\hline Female & 103 & 52.02 \\
Male & 95 & 47.97 \\
\hline Total & 198 & 100 \\
\hline
\end{tabular}

\subsection{Samples and Sampling Method}

Thirty preschool children were selected randomly from the preschools of the statistical population. From each five preschools in Golestan town, six children were randomly selected and finally 30 children were included in our study.

\subsection{Descriptive Properties of the Statistical Sample}

Fifteen out of 30 preschool children in the statistical sample were educated using Ban Ben Bon (experiment group), and the remaining 15 children were educated using a traditional educating method (control group).

\section{Table 2}

Distribution of the statistical sample based on group

\begin{tabular}{lccc}
\hline Group & Frequency & Percentage & Accumulated percentage \\
\hline Experiment & 15 & 50 & 50 \\
Traditional & 15 & 50 & 100 \\
\hline Total & 30 & 100 & --- \\
\hline
\end{tabular}

\subsection{Distribution of the experiment group}

Among 15 children in the experiment group, 7 children were male and 8 children were female.

Table 3

Distribution of the experiment group based on sex

\begin{tabular}{lccc}
\hline Sex & Frequency & Percentage & Accumulated percentage \\
\hline Male & 7 & 47.7 & 46.7 \\
Female & 8 & 53.3 & 100 \\
\hline Total & 15 & 100 & --- \\
\hline
\end{tabular}


Distribution of the traditional group based on sex included 8 males and 7 females. Among 15 children in the traditional group, 8 were male and 7 were female.

\section{Table 4}

Distribution of the traditional group based on sex

\begin{tabular}{lccc}
\hline Sex & Frequency & Percentage & Accumulated percentage \\
\hline Male & 8 & 53.3 & 53.3 \\
Female & 7 & 46.7 & 100 \\
\hline Total & 15 & 100 & --- \\
\hline
\end{tabular}

\subsection{Research Tools}

The Torrance test of creative thinking was used to measure the creativity of children because the children are not able to read at this age, and use painting to conduct the test (see appendix).

The function test was used to measure language learning and reading skill in preschool children.

\subsection{Validity and Reliability of the Test}

In order to evaluate the validity of the function test, a questionnaire including 11 various questions regarding reading skill was used. This questionnaire had been developed by the researcher under the supervision of professors and experts of this field. In order to evaluate the reliability of the questionnaire, the content reliability was considered. A list composed of 11 questions of the questionnaire were presented to five professors and experts of the field, and they were asked to choose one of the choices among completely agree, agree, no idea, disagree, and completely disagree for each question. Following applying the necessary changes and modifications, the final list was produced and used in the study.

Reliability of the function test was calculated using Cronbach's alpha which was 0.81 in this study and was considered as a good reliability.

\section{Data Analysis}

In order to analyze the data, descriptive and inferential statistics were used. In the descriptive statistics, the frequencies were presented based on sex and group. The average scores and standard deviation were also presented in the descriptive statistics.

In the inferential analysis, the covariance analysis was used, and the two prerequisites (e.g. homogeneity of the slope of regression line and equality of the variances of the groups) were considered.

\subsection{Investigating the Hypotheses}

The first hypothesis of the study: The educating method of Ban Ben Bon has a significant effect on the creativity of male and female preschool children. In order to investigate this hypothesis, the covariance analysis test was used. This test had two prerequisites as follows: 1. Homogeneity of the slope of regression line, 2. Equality of the variances of the groups. Based on our investigation, these two prerequisites were observed.

\section{Table 5}

The effect of the educating method of Ban Ben Bon on creativity of male and female preschool children

\begin{tabular}{|c|c|c|c|c|c|}
\hline Source of variation & Sum of squares & Degree of freedom & Mean square & $\begin{array}{c}\text { F- } \\
\text { value }\end{array}$ & $\begin{array}{c}\text { Significance } \\
\text { level }\end{array}$ \\
\hline Effect of creativity pretest & 11403.912 & 1 & 11403.912 & 16.073 & 0.000 \\
\hline The main effect of sex & 63.352 & 1 & 63.352 & 0.089 & 0.768 \\
\hline The main effect of training style & 1924.860 & 1 & 1924.860 & 2.713 & 0.112 \\
\hline
\end{tabular}




\begin{tabular}{lccccc}
\hline $\begin{array}{l}\text { The interactive effect of sex and } \\
\text { training style }\end{array}$ & 34.082 & 1 & 34.082 & 0.048 & 0.828 \\
$\begin{array}{l}\text { The effect of error } \\
\text { Total }\end{array}$ & 17737.320 & 25 & 709.493 & --- & --- \\
\hline As & 34417.367 & 29 & --- & --- & --- \\
\hline
\end{tabular}

As seen in the first row of the table, F-value is 16.073, degree of freedom is 1.25 and the effect was found to be significant at significance level of 0.000 , and since the accepted level for significance is less than 0.05 , it can be concluded that there was a significant difference between the experiment and control group in the pretest with respect to creativity. In other words, the two groups had a significant difference with respect to creativity before conducting the educating method of Ban Ben Bon.

As seen in the second row of the table, $\mathrm{F}$ is 0.089 , degree of freedom is 1.25 , and the effect was significant at 0.768 , and since the accepted significance level is more than 0.05 , it can be concluded that there was not a significant difference between the male and female groups with respect to creativity after removing the effect of pretest. In other words, the educating method of Ban Ben Bon had the same effect on the creativity of male and female children, and gender had no significant role on the effect of Ban Ben Bon on creativity of children.

The second hypothesis: The educating method of Ban Ben Bon has a significant effect on language learning in male and female preschool children.

Similar to Table 5, F is 3.957 , degree of freedom is 1.25 , and the effect was significant at 0.06 , and since the accepted significance level is more than 0.05 , therefore, it can be concluded that there was not a significant difference between the experiment and control groups with respect to the score of language in the pretest. In other words, the two groups were not statistically different with regard to language before conducting the educating method of Ban Ben Bon.

In the next stage, it was seen that $\mathrm{F}$ is 0.116 , degree of freedom is 1.25 , and the effect was significant at 0.736 , and since the accepted significance level is more than 0.05 , therefore, it can be concluded that there was not a significant difference between the male and female groups with respect to the score of language in the posttest after removing the effect of pretest. In other words, conducting the Ban Ben Bon method had the same effect on the male and female groups with respect to their progress in language. In other words, the sex of children had no significant role on the effect of Ban Ben Bon on progress of children in language.

The third hypothesis: The educating method of Ban Ben Bon has a significant effect on innovation of male and female preschool children.

It is seen that $\mathrm{F}$ is 6.93 , degree of freedom is 1.25 , and the effect is significant at 0.01 , and since the accepted significance level is less than 0.05 , therefore, it can be concluded that there was a significant difference between the experiment and control groups with respect to innovation in the pretest. In other words, there was a significant difference between the two groups with respect to innovation in the pretest, and the two groups were statistically different with regard to innovation before conducting the Ban Ben Bon method.

Similarly, it is seen that $\mathrm{F}$ is 0.001 , degree of freedom is 1.25 , and the effect was significant at 0.98 , and since the accepted significance level is more than 0.05 , therefore, it can be concluded that there was no significant difference between the male and female groups regarding the innovation in the posttest after removing the effect of pretest. In other words, conducting Ban Ben Bon test had the same effect on the innovation of male and female groups, and the sex of children had no significant role on the effect of Ban Ben Bon method in children's creativity.

The fourth hypothesis: The educating method of Ban Ben Bon has a significant effect on flexibility of male and female preschool children. 
As seen in the table, $\mathrm{F}$ is 2.61 , degree of freedom is 1.25 , and the effect is significant at 0.11 , and since the accepted significance level is more than 0.05 , therefore, it can be concluded that there was no significant difference between the experiment and control groups with respect to flexibility in the pretest. In other words, the two groups had no significant difference regarding the flexibility before conducting Ban Ben Bon method.

Similarly, $\mathrm{F}$ is 0.008 , degree of freedom is 1.25 , and the effect is significant at 0.93 , and since the accepted significance level is more than 0.05 , therefore, it can be concluded that there was no significant difference between male and female groups regarding the flexibility in the posttest after removing the effect of pretest. In other words, conducting Ban Ben Bon method had the same effect on the flexibility of male and female groups, and sex of the children had no significant role in the effect of Ban Ben Bon method on their flexibility.

The fifth hypothesis: The educating method of Ban Ben Bon has a significant effect on fluidity of male and female preschool children.

As seen in the table, $\mathrm{F}$ is 3.44 , degree of freedom is 1.25 , and the effect is significant at 0.07 , and since the accepted significance level is more than 0.05 , therefore, it can be concluded that there was no significant difference between the experiment and control groups with respect to fluidity in the pretest. In other words, the two groups were not significantly different regarding the fluidity before conducting Ban Ben Bon test.

As seen in the table, $\mathrm{F}$ is 0.02 , degree of freedom is 1.25 , and the effect was significant at 0.86 , and since the accepted significance level is more than 0.05 , therefore, it can be concluded that there was no significant difference between male and female groups regarding the fluidity in the posttest after removing the effect of pretest. In other words, conducting Ban Ben Bon method had the same effect on the fluidity of male and female groups, and sex of the children had no significant role in the effect of Ban Ben Bon method on their fluidity.

The sixth hypothesis: The educating method of Ban Ben Bon has a significant effect on extension extent of male and female preschool children.

As seen in Table 5, F is 16.21, degree of freedom is 1.25 , and the effect was significant at 0.000 , and since the accepted significance level is less than 0.05 , therefore, it can be concluded that there was a significant difference between the experiment and control groups with respect to extension extent in the pretest. In other words, the two groups were significantly different regarding the extension extent before conducting Ban Ben Bon method.

As seen in the table, $\mathrm{F}$ is 0.12 , degree of freedom is 1.25 , and the effect is significant at 0.72 , and since the accepted significance level is more than 0.05 , therefore, it can be concluded that there was no significant difference between male and female groups regarding the extension extent in the posttest after removing the effect of pretest. In other words, conducting Ban Ben Bon method had the same effect on the extension extent of male and female groups, and sex of the children had no significant role in the effect of Ban Ben Bon method on their extension extent.

\section{Conclusion and future Studies}

The present study has conducted on preschool children living in Golestan Town, Shiraz, Iran. The aim of this study was to study the effectiveness of the educating method of Ban Ben Bom on language learning and creativity of preschool children. In this town, there were five preschools and the statistical population included 198 children. The sample group consisted of 30 children which were selected randomly from the preschools of Golestan town, Shiraz. In order to conduct the sampling, six children were selected from each five preschools, and finally 30 children were included in the study. These 30 children were randomly divided into two groups each of which included 15 children. One of the groups was educated 
using Ban Ben Bon method, and the other group was educated using a traditional method. Then the two groups (the experiment and control group) took into an exam to examine the effect of Ban Ben Bon on their creativity and language learning.

The research tools included test of creative thinking which was composed of three activities. In the first activity which was the imagining test, the subject was asked to use a curve-like shape with bright color as the starting point and draw an exclusive picture which tells an interesting story.

The second activity included 10 incomplete figures. The subject was asked to draw and name some pictures using them.

The third activity included 180 separate pairs of parallel lines and the subjects were asked to use them as the starting point and then draw various pictures using them.

Each activity should be finished in 10 minutes. Results have shown that the educating method of Ban Ben Bon had insignificant effect on creativity of preschool children, and among the four elements of creativity (flexibility, innovation, extension and fluidity), it just significantly affected innovation.

The other research tool used in the study was the function test. The function test included 11 questions. Six children were selected randomly from each five preschools and they were asked to take the function exam. Fifteen out of 30 children were selected randomly and educated using Ban Ben Bon method (experiment group), and the other 15 children were educated using the traditional methods (control group). Educating using Ban Ben Bon method lasted for 3 months. The obtained results showed that the educating method of Ban Ben Bon had significant effect on reading which is considered as one of the elements of language learning. For the future studies, it is suggested to conduct a study on a larger sample. Also classifying the children based on the education of their parents to have a more homogenous sample can be further considered.

\section{References}

Ahmadi, AA., Emamipour, Z. (2013). A study on relationship between organizational climate and creativity, Management Science Letters (3), 2709- 2716.

Craft, A. (2001). An analysis of research and literature on creativity in education. Qualifications and Curriculum Authority, 1-37.

Chae, S. (2003). Adaptation of a picture-type creativity test for pre-school children. Language Testing, 20(2), 179-188.

Craft, A. (2003). The limits to creativity in education: Dilemmas for the educator. British journal of educational studies, 51(2), 113-127.

Kemple, K. M., \& Nissenberg, S. A. (2000). Nurturing creativity in early childhood education: Families are part of it. Early Childhood Education Journal, 28(1), 67-71.

Lavrentev, L. (2014). New forms and methods in the pedagogic of art: Creative interaction between children and teacher, Procedia- social and behavioral sciences, 146, 405-409.

McPake, J., Plowman, L., \& Stephen, C. (2013). Pre-school children creating and communicating with digital technologies in the home. British Journal of Educational Technology, 44(3), 421-431.

Plowman, L., \& Stephen, C. (2005). Children, play, and computers in pre-school education. British journal of educational technology, 36(2), 145-157.

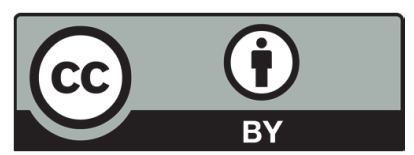

C 2018 by the authors; licensee Growing Science, Canada. This is an open access article distributed under the terms and conditions of the Creative Commons Attribution (CCBY) license (http://creativecommons.org/licenses/by/4.0/). 